\title{
European forest cover since the start of Neolithic agriculture: a critical comparison of pollen-based reconstructions
}

\author{
Jessie Woodbridge1, R.M. Fyfe', C.N. Roberts', A.K. Trondman², F. Mazier ${ }^{3}$ and B. Davis ${ }^{4}$
}

\section{Europe was extensively wooded prior to the arrival of Neolithic agriculture. Forests have since been cleared and fragmented by humans. Here we compare different approaches to transforming fossil pollen data into quantitative} past forest cover estimates on a continental scale.

Pollen-based reconstruction of past European vegetation in quantitative terms has been the focus of several research projects in recent years. A comparison of the results of three such efforts gives insights into the accuracy of different methods (Roberts et al. 2018). Here we summarize the methods, outcomes and their implications. The approaches include, firstly, a mechanistic model of the pollen-vegetation relationship (REVEALS; Sugita 2007) taking into account inter-taxonomic differences in pollen morphology, pollen productivity and characteristics of pollen dispersal and deposition. The second dataset derives from a pseudo-biomization (PBM) based approach, which assigns each individual taxon to a "land-cover class" and then allocates each pollen sample to a "biome" (Woodbridge et al. 2014a; Fyfe et al. 2015). The third is a dataset of tree pollen values converted from pollen data using a Plant Functional Type (PFT) approach (Davis et al. 2015; Fig. 1). The reconstructed vegetation datasets that are used in this comparison are primarily based on the fossil and modern European Pollen Databases (EPD and EMPD; Leydet et al. 2007-2017; Davis et al. 2013), alongside new chronologies produced by Giesecke et al. (2014). The REVEALS approach is the most complex of the three methods and requires pollen productivity values for the major plants involved in the vegetation reconstruction. Here we use the REVEALS reconstructions published by Trondman et al. (2015) for five time windows of the past 6000 years. The PBM and PFT methods are simpler and do not require values of pollen productivity. They can be more easily applied on broad spatial scales to provide time-continuous vegetation reconstructions.

\section{Comparing vegetation reconstructions}

For this comparison, Europe has been divided into three broad climatic-ecological zones, namely Mediterranean, northern and mid-latitude Europe, with results presented for the latter two regions (Fig. 1). Estimates

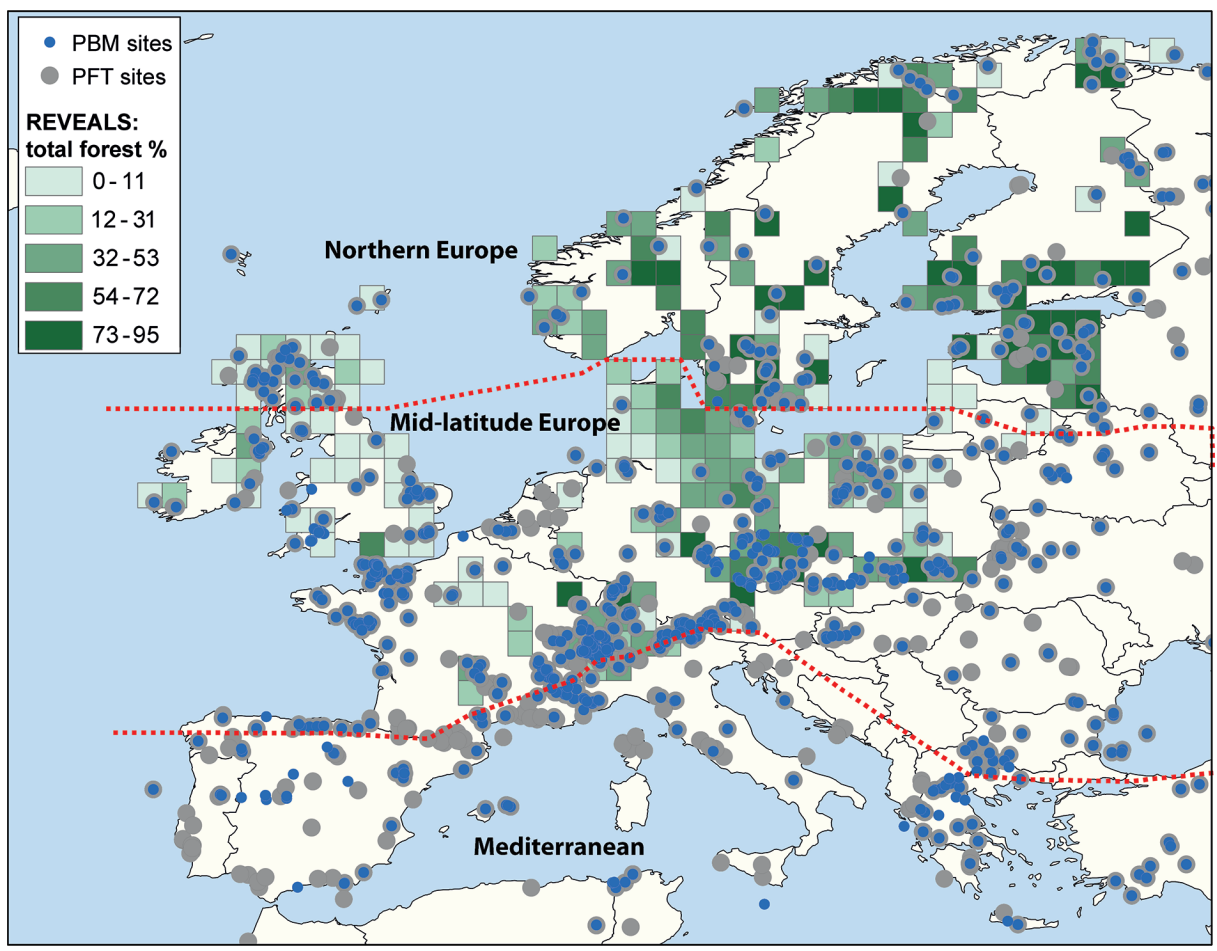

Figure 1: Pollen sites used in the PBM and PFT analyses, and REVEALS estimates for total forest cover percentage. Red dashed lines represent the separate regions analyzed: i.e. northern and mid-latitude Europe. of Holocene vegetation change, using the different approaches, show broadly similar trends for mid-latitude and northern Europe (Fig. 2). The period of maximum forest occurred between approximately 8200 to $6000 \mathrm{BP}$, followed by a progressive decline in forest cover that accelerated after around 1200 BP (early Medieval times). The PBM PFT and REVEALS reconstructions show remarkably similar reconstructions for total forest cover in mid-latitude Europe. They reveal that the percentage of forest cover has declined more in mid-latitude than in northern Europe over the last 6000 years, from about 65 to $\sim 38 \%$. The mid-latitude zone was originally dominated by broadleaf trees, much of which has now been converted to arable and pasture land, but also by late migrating trees such as spruce, fir and beech. However, within this temperate zone, there were marked inter-regional differences in the timing of forest loss. In particular there were contrasting historical trajectories between north-central Europe, where the majority of forests remained intact until Early Medieval times (although records from some areas, such as coastal Poland, show forest loss earlier), and the UK and Ireland, France and Belgium, where most forests had already been cleared in Bronze and Iron Age times (Woodbridge et al., in press). Reconstructions of Holocene forest cover in the northern boreal zone show less consistency between the different pollenbased methods, with the PFT reconstructions systematically higher than those for REVEALS and PBM (Fig. 2). This reflects the weighting applied to open land-cover classes during the PBM process, which was applied after testing the method using modern surface-pollen samples and comparing against remotely-sensed maps (Woodbridge et al. 2014a), and the lower productivity of open vegetation types accounted for in the REVEALS reconstructions. For all regions of Europe, the PBM reconstructions show that the loss of broad-leaf forest has been more pronounced than that of needle-leaf forest (Fig. 2c). This is also shown by the REVEALS reconstructions performed in mid-latitude and northern Europe (e.g. Marquer et al. 2017).

Numerous factors have contributed to vegetation change and forest loss, including 


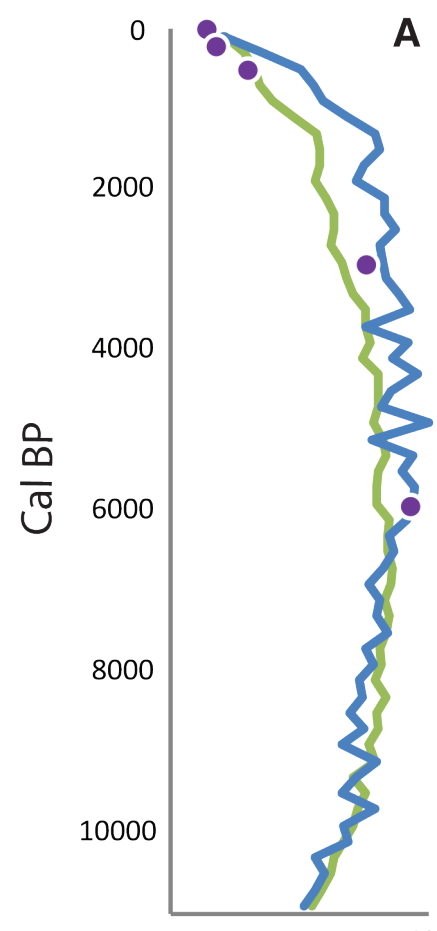

40
A

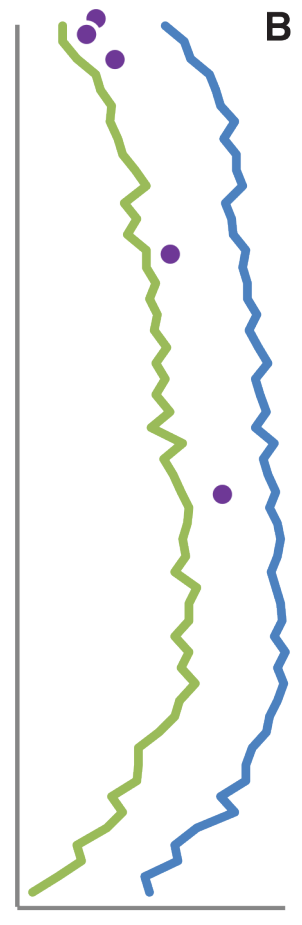

60
B

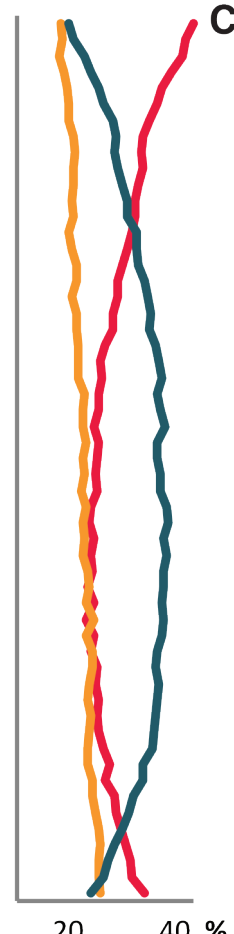

$80 \% \quad 20 \quad 40 \%$

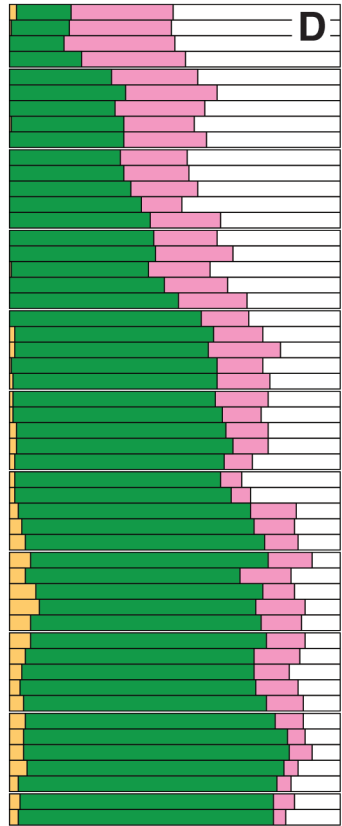

$\begin{array}{llllll}0 & 20 & 40 & 60 & 80 & \%\end{array}$

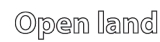

Dwarf shrub

Broad-leaf trees

Needle-leaf trees

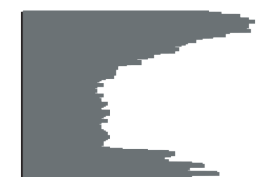

$\mathbf{F}$

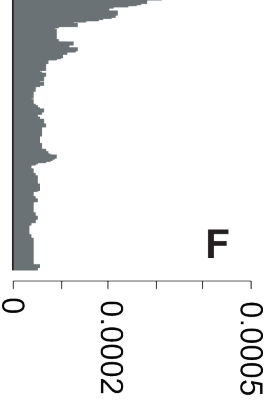

${ }^{14} \mathrm{C}$ date density

PFT (\% Arboreal Pollen)

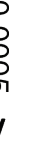

\section{PBM score: closed (forests) sum $\longrightarrow$ PBM score: Needle-leaf forest}

Reveals: tree sum

PBM score: Broad-leaf forest

Figure 2: Pollen-inferred forest cover for: (A) mid-latitude and; (B) northern Europe using the PBM, PFT and REVEALS approaches for the same grid cells; (C) PBM scores for pasture/arable and disturbed land, broad-leaf forest and needle-leaf forest during the last 11,000 years for all reagions. (D) UK and Ireland REVEALS estimates for key vegetation types, and; (E) summed probability distributions of normalized archaeological radiocarbon dates in the UK (Woodbridge et al. 2014b).

climatic changes and long-term ecological dynamics, along with forest conversion to agricultural and grazing lands. Early Holocene pasture/arable and disturbed land PBM scores represent natural vegetation dynamics. An increase in pasture, arable and disturbed land (indicated by the PBM scores for these land-cover classes) is evident from 4000 BP, i.e. Bronze Age (Fig. 2c). This accelerates in the most recent 2000 years, and indicates an increase in agricultural land broadly in line with the loss of forest. Focusing on sub-regions can allow exploration of patterns between vegetation and demographic change. Patterns of demographic change in human societies can be inferred from the density of ${ }^{14} \mathrm{C}$ dates from archaeological sites, which is shown here for the UK (Fig. 2e; Woodbridge et al. 2014b), and indicate an increase in human populations after $6000 \mathrm{BP}$ following the appearance of Neolithic farming. This pattern is reflected in the loss of forests and opening of vegetation indicated by REVEALS reconstructions (Fig. 2d).

\section{Future priorities for pollen and land-cover research}

The impacts of past human populations in transforming natural vegetation have major significance for understanding long-term forest dynamics and for future conservation and management of such resources. For instance, this allows habitats that could be more resilient or at risk from future environmental change to be identified. Future research needs to focus on developing the links between fossil pollen assemblages and land cover in regions where these relationships are not yet so well understood, for example, through obtaining values of pollen productivity for major plants in the Mediterranean region. A greater number of reliable pollen datasets with good chronologies are needed to further develop understanding of vegetation, land-cover and land-use changes, especially in areas where current data coverage is poor. Improved spatial coverage would also allow models of anthropogenic land-cover change to be better evaluated. Different approaches to vegetation reconstruction allow testing of the differing abilities of these methods to sense landscapes. REVEALS offers a quantified and spatially-explicit approach, which is valuable to branches of sciences that require detailed information about past land cover, such as climatologists (Gaillard et al. 2010). Advances have been made in quantifying the effects of past land use and climate on European vegetation change (e.g. Marquer et al. 2017) and in producing forest reconstructions based on the Modern Analog Technique (MAT) through coupling modern pollen samples with satellite-based forest cover (Zanon et al. 2018). Furthermore, in diverse heterogeneous landscapes, such as the Mediterranean, the use of cluster analysis can offer useful results for exploring past vegetation change (Fyfe et al. 2018). PBM and PFT-based methods provide descriptive accounts of vegetation and land-use changes, which can provide valuable comparisons with datasets that give information about disturbance in the past, such as paleoclimate records, fire history trends, and shifts in past human populations inferred from archaeological site densities. Such comparisons will be of value in further deciphering the causes of long-term land-cover change.

\section{ACKNOWLEDGEMENTS}

We are grateful to the many funding bodies and institutions that have supported the different research groups that created the datasets used in this study and all contributors to the databases utilized.

\section{AFFILIATIONS}

'School of Geography, Earth and Environmental Sciences, Plymouth University, UK

${ }^{2} \mathrm{~S}$ chool of Natural Sciences, Linnaeus University, Kalmar, Sweden

${ }^{3}$ GEODE UMR 5602, University Toulouse Jean Jaurès, France

${ }^{4}$ Institute of Earth Surface Dynamics, University of Lausanne, Switzerland

\section{CONTACT}

Jessie Woodbridge: jessie.woodbridge@plymouth. ac.uk

\section{REFERENCES}

Davis BAS et al. (2013) Veg Hist Archaeobot 22: 521-530 Davis BAS et al. (2015) Veg Hist Archaeobot 24: 303-317 Fyfe RM et al. (2015) Glo Change Biol 21: 1197-212 Fyfe RM et al. (2018) Veg Hist Archaeobot 27: 351-364 Gaillard M-J et al. (2010) Clim Past 6: 483-499

Giesecke T et al. (2014) Veg Hist Archaeobot 23: 75-86 Leydet M (2007-2017) The European Pollen Database. http://www.europeanpollendatabase.net

Marquer L et al. (2017) Quat Sci Rev 171: 20-37

Roberts N et al. (2018) Sci Rep 8: 716

Sugita S (2007) Holocene 17: 229-241

Trondman A-K et al. (2015) Glob Change Biol 21: 676-697

Woodbridge J et al. (in press) Late Antique Archaeol

Woodbridge J et al. (2014a) J Biogeogr 41: 2080-2092 Woodbridge J et al. (2014b) J Archaeol Sci 51: 216-224 Zanon M et al. (2018) Front Plant Sci 9: 253 